\begin{tabular}{|l|l|}
\hline $\begin{array}{l}\text { Postprint } \\
\text { Version }\end{array}$ & 1.0 \\
\hline Journal website & http://informahealthcare.com/doi/abs/10.3109/0167482X.2015.1009033 \\
\hline Pubmed link & $\underline{\text { http://www.ncbi.nlm.nih.gov/pubmed/?term=25777750 }}$ \\
\hline DOI & $10.3109 / 0167482 X .2015 .1009033$ \\
\hline
\end{tabular}

This is a NIVEL certified Post Print, more info at http://www.nivel.eu

\title{
Communication at an online infertility expert forum: provider responses to patients' emotional and informational cues
}

\author{
J. W. M. Aarts, A. M. van Oers, M. J. Faber, B. J. Cohlen, W. L. D. M. Nelen, J. A. M. \\ KREMER, AND A. M. VAN DULMEN \\ 1Department of Obstetrics and Gynecology, Radboud University Medical Center, \\ Nijmegen, The Netherlands, \\ 2Scientific Institute for Quality of Healthcare, Radboud University Medical Center, \\ Nijmegen , The Netherlands, \\ 3Fertility Clinic, Isala clinics, Zwolle, The Netherlands, \\ 4Netherlands Institute for Health Services Research, Utrecht, the Netherlands, \\ 5Department of Primary and Community Care, Radboud University Medical Center, \\ Nijmegen, The Netherlands, and \\ 6Department of Health Science, Buskerud University College, Drammen, Norway
}

\begin{abstract}
Online patient-provider communication has become increasingly popular in fertility care. However, it is not known to what extent patients express cues or concerns and how providers respond. In this study, we investigated cues and responses that occur in online patient-provider communication at an infertilityspecific expert forum. We extracted 106 threads from the multidisciplinary expert forum of two Dutch IVF clinics. We performed the following analyses: (1) thematic analysis of patients' questions; and (2) rating patients' emotional and informational cues and subsequent professionals' responses using an adaptation of the validated Medical Interview Aural Rating Scale. Frequencies of themes, frequencies of cues and responses, and sequences (what cue is followed by what response) were extracted. Sixty-five infertile patients and 19 providers participated. The most common themes included medication and lifestyle. Patients gave more informational than emotional cues (106 versus 64). Responses to informational cues were mostly adequate (61\%). The most common response to emotional cues was empathic acknowledgment (72\%). Results indicate that an online expert forum could have a positive effect on patient outcomes, which should guide future research. Offering infertile patients
\end{abstract}


Aarts, J.W.M., Oers, A.M., Faber, M.J., Cohlen, B.J., Nelen, W.L.D.M., Kremer, J.A.M., Dulmen, A.M. van. Communication at an online infertility expert forum: provider responses to patient's emotional and informational cues. Journal of Psychosomatic Obstetrics and Gynaecology 2015

an expert forum to communicate with providers can be a promising supplement to usual care in both providing information and addressing patients' concerns.

\section{Introduction}

In meeting patients' preferences and wishes, care providers increasingly offer online communication opportunities [1-4]. In reproductive medicine, patients are known for using public online peer support forums [5]. However, they also increasingly prefer to communicate online with their healthcare providers on expert forums or in chat rooms, which offer an additional channel for the provision of more information about infertility diagnosis before or after their doctor's appointment [ㅆ, $\underline{6}, \underline{7}]$. For instance, patients sometimes come up with questions after the medical encounter once they have had time to reflect upon the information received $[2,5]$. Another study found that e-mail communication could also facilitate emotional support communication between patients and their providers [8]. Patients can, for instance, be reluctant to discuss sensitive issues during outpatient visits or by telephone, and feel more comfortable doing so online $[\underline{2}, \underline{5}, \underline{8}, \underline{9}]$. It is even suggested that writing about stressful experiences could lead to reduction of physical or psychosocial symptoms [10]. Importantly, patients expressed the need for (online) emotional support from their care providers [11].

However, previous studies in the fertility care setting examining the content of an expert forum and chat room showed that patients mainly discuss factual information instead of the threat of childlessness or other emotional issues [1, $\underline{4}$ ]. We know from face-to-face communication that patients in general are often hesitant in expressing emotional support needs and are more likely to disclose their concerns indirectly [12-14]. These concerns can thus also be covertly present in online patient-doctor communication. If so, such cues are important to recognize in order to reduce feelings of distress $[\underline{12}, \underline{15}]$. This could be especially relevant to infertility care, as suffering from infertility can be as distressing as being confronted with a serious illness [15-17]. Therefore, we sought to examine how providers would attend to emotional and informational cues, such as implicitly disclosed concerns, in an online healthcare setting.

It is crucial that providers respond adequately to both informational and emotional expressions, as this encourages patients to disclose their perspectives on their treatment and concerns [12]. This will increase the chance that patients' preferences can be met, resulting in more patient-centered care. To the best of our knowledge, providers' responses in online communication have not been studied before in reproductive medicine.

Therefore, this study aimed to analyze the content and the process of online communication between patients and their providers at an online infertility-specific expert forum. In particular, we focused on the content and frequency of informational and emotional cues that infertile patients expressed in online utterances to their own medical team. Additionally, we aimed to evaluate the responses to these cues (frequencies and sequences). Based on the aforementioned research, we 
Aarts, J.W.M., Oers, A.M., Faber, M.J., Cohlen, B.J., Nelen, W.L.D.M., Kremer, J.A.M., Dulmen, A.M. van. Communication at an online infertility expert forum: provider responses to patient's emotional and informational cues. Journal of Psychosomatic Obstetrics and Gynaecology-2015

hypothesized that patients would express more informational than emotional cues $[\underline{1}, \underline{4}]$. Furthermore, based on studies using cue and response analysis in face-to-face communication, we hypothesized that providers would respond adequately to informational cues, but would have more trouble picking up emotional cues [12].

\section{METHODS}

\section{Setting}

In the Netherlands, infertility care is mostly publically arranged at three levels. Primary care is provided by the general practitioner (GP) and may conduct part of an initial fertility assessment. Subsequently, the GP can refer couples to a gynecologist in a general (secondary care) or a university (tertiary care) hospital. The gynecologist completes the initial fertility assessment, determines a cause of infertility, and defines a suitable treatment plan. Infertility care is organized around 13 licensed hospitals for in vitro fertilization (IVF) and intracytoplasmic sperm injection (ICSI) (all eight university hospitals, four general hospitals and one private clinic). Ovulation induction (OI) and intra uterine insemination (IUI) are performed in all 93 Dutch hospitals. All OI, IUI cycles and the first three IVF or ICSI treatment cycles are reimbursed by the national healthcare system.

\section{Online infertility-specific expert forum}

Two Dutch IVF-licensed hospitals offered an online clinical infertility community to their patients in addition to usual infertility care. These private, membership-driven online communities are provided by an Internet platform for online health communities, www.mijnzorgnet.nl. The online expert forum that was the focus of interest of the present study is part of both online infertility communities. The expert forum had the format of a bulletin board and thus comprised asynchronous communication. Here patients could post questions to their own medical team (i.e. infertility experts). The medical team represented different disciplines, such as nurses, gynecologists and clinical embryologists. All team members, but also other patient members of the community, could reply. Questions and replies were visible to all members. It was agreed on that the medical team had to reply within 24 hours. For this study, we examined the threads of the expert forum to analyze the online patient-provider communication. Besides the expert forum, the online infertility community also offered a peer support forum for patients to share experiences with each other and provided some basic infertility-related information through blog posts and a media gallery.

To become a member of the online community, patients used their personal digital identification code (i.e. a national standard, supplied by the Dutch government) to create a profile on the platform of www.mijnzorgnet.nl. They were advised to use a nickname. After being registered, patients had to send a membership request to get access to the online infertility community. Access to the online health community 
Aarts, J.W.M., Oers, A.M., Faber, M.J., Cohlen, B.J., Nelen, W.L.D.M., Kremer, J.A.M., Dulmen, A.M. van. Communication at an online infertility expert forum: provider responses to patient's emotional and informational cues. Journal of Psychosomatic Obstetrics and Gynaecology2015

was solely reserved for patients having treatment at the fertility clinic. The community manager used the patient identification number of the hospital to verify if the patient was under treatment at the department. Registration on the website was free of charge. The researchers did not have access to data that would enable them to individually identify the participants.

\section{Ethical approval}

The institutional ethics committee of the Radboud University Medical Center Nijmegen, the Netherlands, reviewed this study project and judged that ethical approval was not required.

\section{Data collection}

We received permission from the community managers of both clinics to extract all expert forums' threads posted between March and June 2011. This was six months after initiation of the online community. These threads were copied to a Word file. We assigned codes to each thread and to each participant to ensure that they could not be identified during analyses.

In February 2012, questionnaires were sent to participants of one of the online health communities to evaluate if the expert forum and providers' responses met their wishes and needs. The questions in this questionnaire were based on five short telephonic patient interviews. Details about these interviews are available from the corresponding author.

\section{Data analysis}

We extracted three types of data from the forum's threads.

First, one researcher (JA) extracted basic background information when available, such as length of threads, use of formal or informal language by patient and respondent, use of "courtesy pronouns", time between question and response, and medical background of the professional who answered.

Second, two researchers experienced in qualitative data analysis conducted a content analysis of patients' threads at the expert forum (AvO, AS). First, both researchers extracted themes independently from a subsample of threads $(n=25)$. Together with a third researcher having expertise in both qualitative analysis and infertility-related medical content, the themes were compared and discussed until consensus was reached. This way a coding manual consisting of these themes could be developed. This manual was used to analyze the remainder of the threads. After coding, the results of both researchers were compared and discussed, together with the third researcher, until consensus was reached. The themes were not modified in this stage.

Third, we performed a cue-response analysis. For this analysis an adaptation of the Medical Interview Aural Rating Scale (MIARS) [18] was applied, which was used in previous studies $[\underline{12}, \underline{19}]$. The MIARS distinguishes emotional cues expressed by 
patients and professionals' responses to each cue. Informational cues were added to the instrument in the adapted format. Per thread, only one informational and one emotional cue was coded (the first-appearing). Two researchers (JA and AvO) independently analyzed frequencies of cues and responses and examined sequences (i.e. what cue is followed by what specific response). Differences were discussed among them until consensus was reached. Both authors have good infertility-related medical knowledge. The possible cue and response categories are defined in Table 1 and will be explained in detail below. Table 2 provides quotations serving as examples of patients' informational and emotional cues.

\section{[TABLE 1][TABLE 2]}

\section{Informational cues and responses}

Informational cues were defined as information-seeking units of texts, including direct questions and indirect statements. Informational cues were categorized as medical, lifestyle-related and practical. We anticipated that patients would also ask questions about the forum or online infertility community itself. We thus added the category "technical". This was in line with other research that evaluated online communication using instruments developed for face-to-face encounters (e.g. RIAS) $[\underline{8}, \underline{20}]$. Responses to informational cues could be graded by relevance as appropriate (i.e. response answered the question with adequate information), little (i.e. information is adequate but would have been better if elaborated) or inappropriate (response does not answer the patient's question). The two authors judged the adequacy of answers based on their infertility-related medical knowledge. Other possible responses to informational cues were coded as distancing (i.e. passing the buck to another person without answering the question), referring (i.e. response stating that the question will be answered later), exploration (i.e. probing questions to find out the exact information the patient needs) and overt blocking responses (i.e. the cue is ignored or the response is not related to the content of the cue).

\section{Emotional cues and responses}

Emotional cues were classified at four levels according to their level of intensity: minimal hints- (E0), hints- (E1), mention- (E2) and clear expression of worry or concern (E3). As emoticons and other typographical expressions (e.g. more than one question mark) are commonly used in online communication and often used for the expression or intensification of emotions [21], we integrated the use of an emoticon into the classification of emotional cues. For instance, an E0 cue became an E1 cue if an emoticon was used. The MIARS protocol distinguishes among three types of responses to emotional cues: exploration (eliciting patient's feeling, clarification of patient's emotion, or educated guess of emotional cue), acknowledgment (empathic statement, reformulating patient's emotion, or giving reassurance) and or distancing (switching focus, passing the buck, giving premature reassurance or inappropriate advice) or blocking further disclosure (i.e. the emotional cue is ignored; content of response does not correlate with cue). The latter two were considered as an inadequate response to emotional cues. 
Aarts, J.W.M., Oers, A.M., Faber, M.J., Cohlen, B.J., Nelen, W.L.D.M., Kremer, J.A.M., Dulmen, A.M. van. Communication at an online infertility expert forum: provider responses to patient's emotional and informational cues. Journal of Psychosomatic Obstetrics and Gynaecology-2015

\section{Coding reliability}

The content analysis and cue-response analysis were performed independently by two researchers. Inter-rater reliability was calculated based on a randomly selected sample of 30 threads. Reliability was tested using intra-class correlation coefficients (ICCs) using a two-way mixed effect model of consistency and single measure statistic. Values between 0.21 and 0.40 can be considered fair, values between 0.41 and 0.60 moderate and values greater than $0.61 \operatorname{good}[\underline{22}$ ].

\section{RESULTS}

\section{Sample}

We identified 106 patient-initiated threads generated by 65 individual patients. Almost all (92\%; $n=60)$ were female. In total, 19 individual healthcare professionals responded to these questions, representing a range of different medical disciplines: two gynecologists, one clinical embryologist, three fertility physicians, eight fertility nurses, one nurse practitioner, three medical assistants and one administrator.

\section{Background characteristics of threads}

The median number of words in patients' expressions was 78 (range 21-307). Three out of the 106 threads were directed at a specific member of the medical team; the others were not specified. The median number of words in professionals' responses was 63 (range 13 to 366 words). Median time between patients' questions and first answer was 15 hours (range 0.13-336). Thirty-six individual patients expressed satisfaction with the professional's response to their question.

\section{Coding reliability}

The ICC for the content analysis was 0.70 (95\% Confidence Interval (CI) 0.51-0.82). The ICC for coding informational cues was 0.92 (95\% CI 0.84-0.96) and 0.81 (95\% CI 0.60-0.92) for emotional cues. The ICC for responses to informational cues was 0.77 (95\% CI 0.59-0.88). Responses to emotional cues showed an ICC of 0.56 (95\% CI 0.22-0.78).

\section{Content analysis}

Most of the threads contained descriptions of the patient's personal situation as an explanation or clarification for their question. Table 3 reports all themes that emerged from the content analysis. Some threads contained more than one theme, resulting in a total of 202 units in 106 threads that were assigned a code. Most frequently patients asked questions about medication and factors that could influence the success of their fertility treatment, such as lifestyle habits. 
Aarts, J.W.M., Oers, A.M., Faber, M.J., Cohlen, B.J., Nelen, W.L.D.M., Kremer, J.A.M., Dulmen, A.M. van. Communication at an online infertility expert forum: provider responses to patient's emotional and informational cues. Journal of Psychosomatic Obstetrics and Gynaecology-2015

\section{Cue and response analysis}

Frequencies of cues and responses

As shown in Table 4, patients gave more informational cues than emotional cues (106 versus 64). All threads contained an informational cue. Informational cues were mostly medical-related (67\%). The majority of the responses provided appropriate information (61\%) and were provided by gynecologists. Exploration of the informational cue was rarely done (5\%). The most common response to emotional cues was acknowledgment (72\%), followed by distancing (16\%).

Example 1: Patient: Are there any patient leaflets with information about the period after the embryo transfer? (Informational cue - practical). This period made me very insecure, I had no idea what I could expect, what could happen to me and what that would mean. I know I can call at any time, and I also know that it is different for every person, but it caused many tears and extra stress. I would like a leaflet with information about all possible scenarios. (Emotional cue - E3)

\section{[TABLE 3][TABLE 4]}

\section{Sequence analysis of cues and responses}

Table 5 shows the types of responses that followed patients' informational and emotional cues. All types of informational cues were responded to appropriately. All types of emotional cues were acknowledged most of the time, but E1 and E2 cues were also distanced from or factually clarified (i.e. less adequate).

Example 2: Patient: Why do I need to put these pills into my vagina [utrogestan]. I am not a big fan of doing that. I never use tampons, because I have bad experiences with inserting things into my vagina. (Emotional cue - E2)

Clinical embryologist: Utrogestan works better if taken vaginally. It supports the endometrium during fertility treatment. (Inadequate response to emotional cue factual clarification)

Example 3: Patient: I have a question about my next IVF treatment. I have just had my first treatment, but my period started today; three days later than expected. Not pregnant unfortunately... Is it a bad thing for my next treatment that my period came three days later? (Informational cue - medical; Emotional cue - E1).

Gynecologist: I am so sorry for you that you're not pregnant:-(. For your next IVF treatment it's no problem that your period came three days later. Good luck! (Adequate response to informational cue; Acknowledgment of emotional cue)

\section{[TABLE 5]}

Cues with multiple responders. 
Aarts, J.W.M., Oers, A.M., Faber, M.J., Cohlen, B.J., Nelen, W.L.D.M., Kremer, J.A.M., Dulmen, A.M. van. Communication at an online infertility expert forum: provider responses to patient's emotional and informational cues. Journal of Psychosomatic Obstetrics and Gynaecology-2015

To the majority of questions, either one healthcare professional or a patient responded. However, fourteen threads consisted of multiple response lags, showing the variability of the expert forum. These threads are presented in Table 6. For instance, in thread no. 10, the first response was distancing and not adequate. The second respondent acknowledged the emotional cue, but provided little information. The third respondent complemented the others by providing appropriate information and addressing the patient's emotional cue.

\section{[TABLE 6]}

\section{Questionnaires on patients' satisfaction with expert forum}

Questionnaires were sent to all 147 members of one of the online health communities. Sixty-five patients completed the questionnaire (44\%), of whom 95\% were female and $28 \%$ were pregnant when filling out the questionnaire. The greater proportion (86\%) had posted 1 to 5 questions at the expert forum. Patients scored the communication on this forum with a mean of 7.9 (SD 0.9, Scale $1-10$ ). The greater proportion of patients was very satisfied with the providers' responses to their questions (Table 7).

\section{[TABLE 7]}

\section{Discussion}

In this study we used content, frequency, and sequence analyses of infertile patients' cues and professionals' responses to examine the communication at the online expert forums of two Dutch IVF clinics. To the best of our knowledge this is an innovative approach of evaluating online patient-provider communication.

First, the thematic content analysis of the threads showed that most of them cover factual topics in line with topics found in these studies [1, $\underline{4}]$. Furthermore, these topics cover themes that seem to lack in traditional patient information leaflets or in face-to-face encounters [23], implying the value of the forum as an additional information channel.

Second, patients expressed both informational and emotional cues. This contrasts somewhat with the studies from van Selm et al. [1] (synchronous communication in chat-module) and Himmel et al. [4] (asynchronous communication at forum), who reported that patients did not express much worry about the threat of childlessness. The sequence analysis in this study revealed that $60 \%$ of patients' threads also included emotional concerns. Compared to other studies evaluating emotional cues in patient-provider e-mail communication, this study's percentage is relatively high. In Roter et al.'s study only in 35\% of messages emotional cues were present [ 8 ] and in the study by Grimsbo et al. the proportion of emotional cues was similar [24]. Compared to face-to-face consultations, in which emotional cues and concerns are sometimes described as rare occurrences, this study's percentage is also relatively high [13]. Several hypotheses could explain this. First, the sensitive and stigmatizing character of being infertile could make patients more reluctant to express their 
emotions and feelings in real-life settings to their physician [ㅁ,ㅁ]. The (relatively) anonymous feature of online communication has been theorized to facilitate and increased self-disclosure [24]. Richards and Vigano [25,26] state in their critical review on online counseling that disinhibition seems to aid patients to express themselves more openly and honestly. Some patients find written expression to be a useful way of sharing concerns $[\underline{9}, \underline{27}, \underline{28}]$. Second, patients sometimes perceive medical consultations in the hospital setting as hurried and stressful, with scant time to discuss all of their questions or concerns [29]. The expert forum allowed patients to write their concerns as they thought of them and choose the setting and timing of expressing their emotions, which is of additional value for daily care practice.

Third, overall, professionals gave adequate responses to patients' informational and to a somewhat lesser extent - emotional cues. This echoes the pattern seen in face-toface patient-provider interactions in oncology $[\underline{12}, \underline{14}]$ and other gynecological settings [30]. However, the responses to emotional cues in these real-life settings were merely facilitations, such as expressing understanding (e.g. "I see” or "hmmm"), whereas in our study, professionals articulated empathic statements, reflection or reassurance (e.g. "I am so sorry to hear that your treatment failed") more often. The absence of visual and verbal cues in online communication conveying information about the person and his/her feelings - could explain this difference. On the one hand, both patients and professionals have to be more explicit in their expressions of concerns or empathy, which could lead to more disclosure of sensitive information and feelings of psychological safety $[\underline{24}, \underline{25}, \underline{26}]$, reducing anxiety levels and improving other patient outcomes $[\underline{12}, \underline{15}, \underline{31}]$. Consequently, they might be more receptive to the information provided both online and offline, resulting in better recall or improved adherence to treatment $[\underline{12}, \underline{32}]$. The results of the questionnaire demonstrated that the majority of patients felt supported and understood, and were encouraged to reveal their concerns to professionals. This underlines the potential added value of online health communication. On the other hand, in $15 \%$ of cases, providers used a distancing strategy in their response (e.g. switching focus), which could lead to negative patient outcomes [31]. Furthermore, Smith et al. suggested that providers' adequate responses to emotions could increase short-term anxiety as a result of disclosing difficult issues [33]. This could imply that further exploration of these cues - instead of solely acknowledging them - is important to decrease anxiety levels. However, exploration was hardly done in this study, and future research should evaluate to what extent these cues and providers' responses could impact patient outcomes. Although these relationships between responses and patient outcomes may not be causal findings, they indicate that professionals may need more guidance in online patient communication. Guidelines for online health communication with patients are not optimally implemented in healthcare [34], and physicians and nurses have expressed the need for educational training [35]. Communication training to professionals should thus not only focus on face-to-face medical consultations but also on online settings, as this is an increasing trend in healthcare.

The expert forum evaluated in this study differs from public peer-supported forums or communities for infertile patients studied by others $[\underline{27}, \underline{28}, \underline{36}]$. Patients feel emotionally supported in peer forums, yet they also express the need for emotional 
support from their care providers [11,37]. Hence, it is possible that patients' respond or express themselves differently depending on the forum type, and that they use the two types in a complementary fashion. Moreover, the participation of different medical disciplines in this expert forum is a strength which places the cure model (associated with physicians) and the care model (associated with nurses) on a continuum, supporting a comprehensive approach to patient care and responding to patients' needs $[\underline{11}, \underline{38}]$. Unfortunately, clinical psychologists or social workers have not participated in this study's expert forums yet, but could be of important value in this comprehensive care model.

Some limitations of this study should be discussed. First, coding emotional cues and subsequent responses appeared to be challenging. The reliability of emotional cues and the professionals' responses was moderate, whereas the reliability of informational cues and responses was good. However, sequence analysis appeared to be useful to detect patients' (indirect) concerns in online communication. Second, a caveat of sequence analysis is that the level of adequacy of responses was based on experts' views. The short questionnaire showed agreement with patients' experiences. However, future studies should explore patients' expectations and experiences of professionals' responses to their questions in more detail. Third, external validity of our findings may be limited, because we focused on a specific setting. However, infertility is an upsetting and difficult life experience. Although infertility is not life threatening, the invasive and often lengthy treatment and the threat of chronic childlessness can have an impact on patients' well being similar to other severe health conditions $[\underline{16}, \underline{39}, \underline{40}]$.

In conclusion, infertile patients express both informational and emotional cues in online communication with their providers. The providers responded mostly adequately to these cues, often with an explicitly empathic comment. This shows that an online expert forum could have a positive effect on patient outcomes: a finding that should be explored in future research. Offering infertile patients an expert forum in which they communicate with their providers can be a promising supplement to usual care, by both providing information and addressing patients' concerns and emotional distress during fertility treatment.

Current knowledge on this subject

- Online communication with healthcare professionals is becoming increasingly popular among patients, particularly in fertility care.

- It is not known what types of cues and concerns patients express in an infertility expert forum.

- Furthermore, the additional value of online communication to usual care is not clear.

What this study adds

- Patients express both informational and emotional cues to their healthcare providers in an online expert forum. 
- Healthcare professionals were capable of responding adequately to both types of cues most of the time, which could lead to positive patient experiences and positive patient outcomes.

- Offering infertile patients an expert forum in which they communicate with their providers can be a promising supplement to usual care in both providing information and addressing patients' concerns and emotional distress during fertility treatment.

Acknowledgments

We acknowledge Mrs. A. Spijker for her cooperation in the content analysis of patients' threads for which she was financially compensated.

We acknowledge Mrs. M. Kuijs, MSc, for her help in distributing and analyzing the questionnaires on patients' evaluations of the expert forum.

\section{Declaration of interest}

The authors report no conflicts of interest.

\section{REFERENCES}

1. Van Selm M, Tuil W, Verhaak C, et al. Chat about what matters most: an analysis of chat contributions posted to an outpatient fertility website. Cyberpsychol Behav 2008;11:675-7

2. McGeady $\mathrm{D}$, Kujala J, Ilvonen $\mathrm{K}$. The impact of patient-physician web messaging on healthcare service provision. Int J Med Inform 2008;77:17-23

3. Stoop AP, van't Riet A, Berg M. Using information technology for patient education: realizing surplus value? Patient Educ Couns 2004;54:187-95

4. Himmel W, Meyer J, Kochen MM, Michelmann HW. Information needs and visitors' experience of an Internet expert forum on infertility. J Med Internet Res 2005;7:e20

5. Aarts JW, van den Haak P, Nelen WL, et al. Patient-focused Internet interventions in reproductive medicine: a scoping review. Hum Reprod Update 2012;18:211-27

6. Weissman A, Gotlieb L, Ward S, et al. Use of the internet by infertile couples. Fertil Steril 2000;73:1179-82

7. Haagen EC, Tuil W, Hendriks J, et al. Current Internet use and preferences of IVF and ICSI patients. Hum Reprod 2003;18:2073-8

8. Roter DL, Sands DZ, Ford DE, Houston T. Can e-mail messages between patients and physicians be patient-centered? Health Commun 2008;23:80-6

9. Strasser F, Fisch M, Bodurka DC, et al. E-motions: email for written emotional expression. J Clin Oncol 2002;20:3352-5

10. Smyth JM, Stone AA, Hurewitz A, Kaell A. Effects of writing about stressful experiences on symptom reduction in patients with asthma or rheumatoid arthritis: a randomized trial. JAMA 1999;281:1304-9

11. Dancet EA, Van Empel IW, Rober P, et al. Patient-centred infertility care: a qualitative study to listen to the patient's voice. Hum Reprod 2011;26:827-33

12. Jansen J, van Weert JC, de Groot J, et al. Emotional and informational patient cues: the impact of nurses' responses on recall. Patient Educ Couns 2010;79:218-24

13. Zimmermann C, Del Piccolo L, Finset A. Cues and concerns by patients in medical consultations: a literature review. Psychol Bull 2007;133:438-63

14. Butow PN, Brown RF, Cogar S, et al. Oncologists' reactions to cancer patients' verbal cues. Psychooncology 2002;11:47-58 
15. Verhaak CM, Smeenk JM, Evers AW, et al. Women's emotional adjustment to IVF: a systematic review of 25 years of research. Hum Reprod Update. 2007;13:27-36

16. Hammarberg K, Astbury J, Baker H. Women's experience of IVF: a follow-up study. Hum Reprod. 2001;16:374-83

17. Himmel W, Ittner E, Kochen MM, et al. Management of involuntary childlessness. Br J Gen Pract 1997;47:111-18

18. Heaven C, Clegg J, Maguire P. Transfer of communication skills training from workshop to workplace: the impact of clinical supervision. Patient Educ Couns 2006;60:313-25

19. Uitterhoeve R, de Leeuw J, Bensing J, et al. Cue-responding behaviours of oncology nurses in video-stimulated interviews. J Adv Nurs 2008;61:71-80

20. Nelson EL, Miller EA, Larson KA. Reliability associated with the Roter Interaction Analysis System (RIAS) adapted for the telemedicine context. Patient Educ Couns 2010;78:72-8

21. Derks D, Bos AE, von Grumbkow J. Emoticons in computer-mediated communication: social motives and social context. Cyberpsychol Behav 2008;11:99101

22. Altman DG. Practical statistical methods for medical research. London: Chapman and Hall; 1991

23. Van de Belt TH, Hendriks AF, Aarts JW, et al. Evaluation of patients' questions to identify gaps in information provision to infertile patients. Hum Fertil 2014;17:133-40

24. Grimsbo GH, Ruland CM, Finset A. Cancer patients' expressions of emotional cues and concerns and oncology nurses' responses, in an online patient-nurse communication service. Pat Educ Couns 2012;88:36-43

25. Richards D, Vigano N. Online counseling: a narrative and critical review of the literature. J ClinP Psychol 2013;69:994-1011

26. Cook JE, Doyle C. Working alliance in online therapy as compared to face-to-face therapy: preliminary results. Cyberpsychology 2002;5:95-105

27. Malik S, Coulson NS. The therapeutic potential of the internet: exploring self-help processes in an internet forum for young people with inflammatory bowel disease. Gastroenterol Nurs 2011;34:439-48

28. Malik SH, Coulson NS. Computer-mediated infertility support groups: an exploratory study of online experiences. Patient Educ Couns 2008;73:105-13

29. Van Empel IW, Nelen WL, Tepe ET, et al. Weaknesses, strengths and needs in fertility care according to patients. Hum Reprod 2010;25:142-9

30. Van Dulmen AMN, Langewitz W. Doctor's responses to patients' concerns: an exploration of communication sequences in gynecology. Epidemiologia e Psichiatria Sociale 2003;12:98-102

31. Suggs LS, McIntyre C. Are we there yet? An examination of online tailored health communication. Health Educ Behav 2009;36:278-88

32. Neumann M, Wirtz M, Bollschweiler E, et al. Determinants and patient-reported longterm outcomes of physician empathy in oncology: a structural equation modelling approach. Patient Educ Couns 2007;69:63-75

33. Smith A, Juraskova I, Butow $P$, et al. Sharing vs. caring - the relative impact of sharing decision versus managing emotions on patient outcomes. Pat Educ Couns 2011;82:233-9

34. Ski CF, Thompson DR. Editorial: online health communication in improving outcomes. J Clin Nurs 2011;20:2689

35. Aarts JW, Faber MJ, Cohlen BJ, et al. Lessons learnt from the implementation of an online infertility community into an IVF clinic's daily care practice. Hum Fert 2014

36. Hinton L, Kurinczuk JJ, Ziebland S. Infertility, isolation and the Internet: a qualitative interview study. Pat Educ Couns 2010;81:436-41

37. Van Empel IW, Aarts JW, Cohlen BJ, et al. Measuring patient-centredness, the neglected outcome in fertility care: a random multicentre validation study. Hum Reprod 2010;25:2516-26

38. Baumann AO, Deber RB, Silverman BE, Mallette CM. Who cares? Who cures? The ongoing debate in the provision of health care. J Adv Nurs 1998;28:1040-5 
Aarts, J.W.M., Oers, A.M., Faber, M.J., Cohlen, B.J., Nelen, W.L.D.M., Kremer, J.A.M., Dulmen, A.M. van. Communication at an online infertility expert forum: provider responses to patient's emotional and informational cues. Journal of Psychosomatic Obstetrics and Gynaecology-2015

39. Verhaak CM, Smeenk JM, van Minnen A, et al. A longitudinal, prospective study on emotional adjustment before, during and after consecutive fertility treatment cycles. Hum Reprod 2005;20:2253-60

40. Brandes M, Van der Steen JO, Bokdam SB, et al. When and why do subfertile couples discontinue their fertility care? A longitudinal cohort study in a secondary care subfertility population. Hum Reprod 2009;24:3127-35

\section{TABLES AND FIGURES}

Table 1. Definitions.

Definitions

\section{Thread}

A patient-initiated thread on the expert forum including a patient's utterance (that could consist of an informational cue and/or emotional cue) and subsequent response(s) by one or more healthcare providers.

Cue

Utterances (direct or indirect) made by patients, which suggest that they deem the subject to be important, would like factual clarification, or feel anxious. Indirect and implicit statements would need a clarification from the health provider.

\section{Informational cue}

Information-seeking utterances by patients, including direct and indirect statements. The content of the cue indicates the category, i.e. being medical, lifestyle, practical, or technology-related.

\section{Emotional cue}

Utterances that show a level of an emotion, with a level of intensity, ranging from implicitly (E0) and explicitly expressed concerns (E3).

\section{Cue response}

The response the clinician shows to an informational or an emotional cue. The response could be absent or only minimal. More than one medical team members (including other patients) can respond to the same cue (multiple responses).

\section{Adequate response to informational cue}

A response was rated as adequate if the provided information was complete according to the authors who analyzed the threads. In addition, it had to cover the same issue as raised by the patient's cue. Further exploration of the cue (e.g. asking questions for clarification of the cue) was also considered to be an adequate response. Other responses were considered to be inadequate

\section{Adequate response to emotional cue}

A response was considered to be adequate if the cue was further explored or acknowledged. Other responses were rated inadequate. 
Aarts, J.W.M., Oers, A.M., Faber, M.J., Cohlen, B.J., Nelen, W.L.D.M., Kremer, J.A.M., Dulmen, A.M. van. Communication at an online infertility expert forum: provider responses to patient's emotional and informational cues. Journal of Psychosomatic Obstetrics and Gynaecology 2015

Table 2. Examples of informational and emotional cues based on quotations.

\begin{tabular}{|c|c|}
\hline Cues & Example \\
\hline \multicolumn{2}{|l|}{ Informational cue } \\
\hline Medical & $\begin{array}{l}\text { "My GP prescribed me Arthrotec tablets for a bursitis. I have to inject Pregnyl soon, can I use the Arthrotec safely when } \\
\text { I am using Pregnyl?", }\end{array}$ \\
\hline Lifestyle-related & "We would like to go on holiday to Egypt. Could the high temperatures there have a negative effect on semen quality?", \\
\hline Practical & "Is it correct that I can inject myself only twice with each Gonal-F pen? I think I don't have enough pens."' \\
\hline Technology-related & "'We get an error notification, if we try to log on to the website. Can you help us?' \\
\hline \multicolumn{2}{|l|}{ Emotional cue } \\
\hline E0 & “'We're undergoing our sixth intra-uterine insemination." \\
\hline E1 & $\begin{array}{l}\text { "What is your opinion about acupuncture? I think if it doesn't help in getting pregnant, it might help me relax more during } \\
\text { treatment." } \\
\text { "I'm having many side-effects of using Utrogestan. I'm very nauseous, dizzy and tired." }\end{array}$ \\
\hline E2 & $\begin{array}{l}\text { "I had my period today. Should I still do the pregnancy test? Will I not be playing mind tricks when testing and hoping it } \\
\text { will be positive? I think it will even hurt more if it turns out to be negative." } \\
\text { "I'm really nervous about my ultrasound next week.", }\end{array}$ \\
\hline E3 & $\begin{array}{l}\text { "The bad news caused many tears and gave us extra stress for the next treatment cycle. We want to have a child soooo } \\
\text { badly!!!!" }\end{array}$ \\
\hline
\end{tabular}

Table 3. Findings content analysis of patients' questions at expert forum $\left(n_{\text {total }}=202\right)$.

Medication (e.g. usage, side-effects)

Factors associated with success of treatment (e.g. age, previous treatment, quality semen, lifestyle)

Practical questions (e.g. contact numbers, insurance, waiting times)

Emotional and psychological consequences

Consequences of an unsuccessful treatment cycle (e.g. blood loss before pregnancy test)

Online infertility community (e.g. login problems, suggestions for improvement)

Information on treatment options in general (e.g. treatments in other clinics, other medication)

Information on diagnostic tests (e.g. home tests)

Clarification of information (received previously at expert forum or at the clinic)

Success percentages of specific fertility treatments (e.g. assisted hatching, ICSI)

Information about scientific research

Other (e.g. development of an embryo)

A thread of one patient could consist of more than one theme. Consequently an informational cue could consist of more than one theme, leading to 202 codes in 106 threads. 
Aarts, J.W.M., Oers, A.M., Faber, M.J., Cohlen, B.J., Nelen, W.L.D.M., Kremer, J.A.M., Dulmen, A.M. van. Communication at an online infertility expert forum: provider responses to patient's emotional and informational cues. Journal of Psychosomatic Obstetrics and Gynaecolog 2015

nivel

Table 4. Frequency of patients' informational and emotional cues and the different types of professionals' responses.

\section{Informational cues}

\begin{tabular}{lr}
\hline Medical & 71 \\
Lifestyle & 12 \\
Practical & 16 \\
Technical, i.e. related to the website & 7 \\
Total & 106
\end{tabular}

106

\begin{tabular}{|c|c|c|c|c|c|c|c|}
\hline Response & Gynecologist & Nurse & $\begin{array}{c}\text { Fertility } \\
\text { physician }\end{array}$ & Embryologist & $\begin{array}{l}\text { Medical } \\
\text { assistant }\end{array}$ & $\begin{array}{l}\text { Other } \\
\text { patient }\end{array}$ & Total \\
\hline Appropriate information & 26 & 27 & 4 & 8 & 6 & 2 & 73 \\
\hline Little information & 10 & 6 & 2 & 0 & 2 & 2 & 22 \\
\hline Inappropriate information & 1 & 2 & 0 & 0 & 1 & 2 & 6 \\
\hline Referring & 0 & 3 & 0 & 0 & 2 & 0 & 5 \\
\hline Distancing & 1 & 1 & 0 & 1 & 4 & 1 & 8 \\
\hline Exploration & 1 & 3 & 1 & 0 & 1 & 0 & 6 \\
\hline Overt blocking & 0 & 0 & 0 & 0 & 0 & 0 & 0 \\
\hline Total & 39 & 42 & 7 & 9 & 16 & 7 & $120^{\mathrm{a}}$ \\
\hline Emotional cues & & & & & & & \\
\hline
\end{tabular}

Minimal hints - E0

Hints - E1

7

Mention - E2

Clear expression of worry or concern $-\mathrm{E} 3 \quad 2$

Total

1
2
16
7
6



10
26
10
1
0
1
1
0
39


7
31
24
2
64

\begin{tabular}{|c|c|c|c|c|c|c|c|}
\hline Response & Gynecologist & Nurse & $\begin{array}{l}\text { Fertility } \\
\text { physician }\end{array}$ & Embryologist & $\begin{array}{l}\text { Medical } \\
\text { assistant }\end{array}$ & $\begin{array}{l}\text { Other } \\
\text { patient }\end{array}$ & Total \\
\hline Acknowledgment & 19 & 24 & 1 & 7 & 2 & 3 & 56 \\
\hline Factual clarification & 3 & 0 & 1 & 0 & 1 & 0 & 5 \\
\hline Distancing & 5 & 5 & 0 & 0 & 2 & 0 & 12 \\
\hline Exploration & 0 & 0 & 0 & 0 & 0 & 0 & 0 \\
\hline Overt blocking & 1 & 1 & 2 & 0 & 1 & 0 & 5 \\
\hline Total & 28 & 30 & 3 & 7 & 6 & 3 & $78^{\mathrm{a}}$ \\
\hline
\end{tabular}

${ }^{a}$ The total numbers of responses to informational and emotional cues respectively, are higher than the total number of both types of cues. Because of the discussion forum format and multidisciplinary character of the expert forum it was possible that more than one person responded to the patient's cue.

Table 5. Sequences: Patients' informational and emotional cues followed by professionals' responses.

\begin{tabular}{|c|c|c|c|c|c|c|}
\hline Informational cues & \multicolumn{6}{|c|}{ Responses } \\
\hline Lifestyle $(n=12)$ & 12 & 2 & 1 & 0 & 0 & 1 \\
\hline Practical $(n=16)$ & 13 & 2 & 0 & 0 & 2 & 1 \\
\hline Technical $(n=7)$ & 5 & 2 & 0 & 0 & 2 & 1 \\
\hline Minimal hints - E0 $(n=7)$ & 6 & 0 & 0 & 0 & 1 & \\
\hline Hints - E1 $(n=31)$ & 28 & 3 & 6 & 0 & 2 & \\
\hline Mention - E2 $(n=24)$ & 20 & 2 & 7 & 0 & 2 & \\
\hline Clear expression of worry or concern $-\mathrm{E} 3(n=2)$ & 2 & 0 & 0 & 0 & 0 & \\
\hline
\end{tabular}

All responses from different respondents to a patient's cue are presented in this table. Consequently, it is possible that one cue was followed by more than one response. 
Aarts, J.W.M., Oers, A.M., Faber, M.J., Cohlen, B.J., Nelen, W.L.D.M., Kremer, J.A.M., Dulmen, A.M. van. Communication at an online infertility expert forum: provider responses to patient's emotional and informational cues. Journal of Psychosomatic Obstetrics and Gynaecology-2015

nivel

Table 6. Patients' cues with multiple respondents.

\begin{tabular}{|c|c|c|c|c|c|c|c|c|}
\hline \multirow[b]{2}{*}{ Thread 1} & \multirow{2}{*}{$\begin{array}{l}\text { Informational } \\
\text { cue }\end{array}$} & \multirow[t]{2}{*}{$\begin{array}{l}\text { Emotional } \\
\text { cue }\end{array}$} & \multicolumn{2}{|c|}{ Respondent 1 (who - how) } & \multicolumn{2}{|c|}{ Respondent 2 (who - how) } & \multicolumn{2}{|c|}{ Respondent 3 (who - how) } \\
\hline & & & Other $\mathrm{pt}$ & Appropriate & Nurse & Appropriate & & \\
\hline Thread 2 & Practical & & Nurse & Appropriate & Fert $\mathrm{Ph}$ & Appropriate & & \\
\hline Thread 3 & Practical & & Nurse & Appropriate & & & & \\
\hline Thread 4 & Medical & & Gyn & Appropriate & Nurse & Appropriate & & \\
\hline & & E1 & Gyn & Acknowledgment & Nurse & Acknowledgment & & \\
\hline Thread 5 & Lifestyle & & Gyn & Appropriate & Other pt & Appropriate & & \\
\hline & & E1 & Gyn & Acknowledgment & Other $\mathrm{pt}$ & Acknowledgment & & \\
\hline Thread 6 & Medical & & Nurse & Appropriate & Other pt & Inappropriate & & \\
\hline Thread 7 & Medical & & Gyn & Appropriate & & & & \\
\hline Thread 8 & Practical & E2 & $\begin{array}{l}\text { Gyn } \\
\text { Nurse }\end{array}$ & $\begin{array}{l}\text { Acknowledgment } \\
\text { Appropriate }\end{array}$ & Other $\mathrm{pt}$ & Acknowledgment & & \\
\hline Thread 9 & Medical & E3 & $\begin{array}{l}\text { Nurse } \\
\text { Med asst }\end{array}$ & $\begin{array}{l}\text { Acknowledgment } \\
\text { Little information }\end{array}$ & $\begin{array}{l}\text { Nurse } \\
\text { Nurse }\end{array}$ & $\begin{array}{l}\text { Acknowledgment } \\
\text { Appropriate }\end{array}$ & Other pt & Acknowledgment \\
\hline Thread 10 & Medical & E1 & Med asst & Distancing & $\begin{array}{l}\text { Nurse } \\
\text { Nurse }\end{array}$ & $\begin{array}{l}\text { Little information } \\
\text { Acknowledgment }\end{array}$ & $\begin{array}{l}\text { Gyn } \\
\text { Gyn }\end{array}$ & $\begin{array}{l}\text { Appropriate } \\
\text { Acknowledgment }\end{array}$ \\
\hline Thread 11 & Practical & E0 & Med asst & Appropriate & $\begin{array}{l}\text { Embr } \\
\text { Embr }\end{array}$ & $\begin{array}{l}\text { Appropriate } \\
\text { Acknowledgment }\end{array}$ & & \\
\hline Thread 12 & Practical & E1 & $\begin{array}{l}\text { Other pt } \\
\text { Other pt }\end{array}$ & $\begin{array}{l}\text { Distancing } \\
\text { Acknowledgment }\end{array}$ & $\begin{array}{l}\text { Fert } \mathrm{Ph} \\
\text { Fert } \mathrm{Ph}\end{array}$ & $\begin{array}{l}\text { Little information } \\
\text { Overt blocking }\end{array}$ & & \\
\hline Thread 13 & Medical & E1 & Other $\mathrm{pt}$ & Distancing & $\begin{array}{l}\text { Other pt } \\
\text { Other pt }\end{array}$ & $\begin{array}{l}\text { Little information } \\
\text { Distancing }\end{array}$ & Other pt & Little information \\
\hline Thread 14 & Medical & E1 & Other pt & Inappropriate & Med ass & Referring & $\begin{array}{l}\text { Nurse } \\
\text { Nurse }\end{array}$ & $\begin{array}{l}\text { Appropriate } \\
\text { Acknowledgment }\end{array}$ \\
\hline
\end{tabular}

Other $\mathrm{pt}=$ Other patient who responded to a question; Gyn=Gynecologist; Fert $\mathrm{ph}=$ Fertility physician; Med asst $=$ Medical assistant; Embr $=$ Clinical embryologist.

Table 7. Patients' experiences with professionals' responses on their questions.

Reasons to ask questions on the expert forum

I ask more questions on the forum than in a face-to-face encounter

I ask questions on the forum that I would not ask in a face-to-face encounter

I ask questions on the forum that I forgot to ask in the face-to-face visit

Evaluation of the provider's answer

The answer led to a new or better understanding $\quad 85$

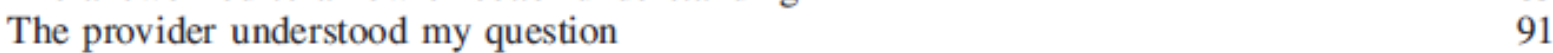

The answer was complete $\quad 89$

The answer reassures me $\quad 92$

The provider showed compassion $\quad 99$

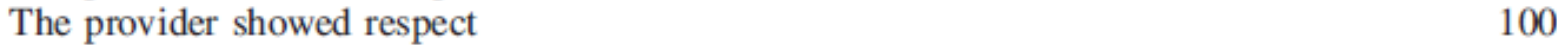

